\title{
Daggers and swords of early Sarmatian shape with ellipsoidal handles in Central Asia
}

\section{Ivanov Sergei Sergeevich}

Candidate of History, Associate professor of Zh. Balasagyn Kyrgyz National University. The Kyrgyz Republic, 720033, Bishkek, st. of Frunze, 547. E-mail: sergioiv@mail.ru.

\begin{abstract}
The article is devoted to distribution of phenomenon on a number of iron daggers and swords of early Sarmatian shape from Central Asia of special type of the handles having the ellisoid form. The highest concentration of similar bladed weapon is fixed in Tien Shan, but separate samples also are in Northern Bactria (the Southern Tajikistan) and in Fergana. Daggers and swords with similar handles are noted in the antiquities of early Sarmatian culture in the Southern Cisurals and Trans-Ural regions and also in the territory of the cultures of Scythian image of Sayan-Altay. The chronology of bladed weapon with similar handles is kept within the IV-III centuries and is the reliable chronological indicator for monuments from which its samples are known.
\end{abstract}

Key words: early nomads; arms; daggers and swords; ellipsoid handles.

\section{Орта Азияның эллипстәрізді тұтқаға ие ертесармат кейпіндегі қанжарлары мен қылыштары}

\section{Иванов Сергей Сергеевич}

тарих ғылымдарының кандидаты, Ж.Баласағұн атындағы Қырғыз ұлттық университетінің доценті. Қырғыз Республикасы, 720033, Бішкек қ, Фрунзе к, 547. E-mail: sergioiv@mail.ru.

\begin{abstract}
Аңдатпа. Мақала жалпы алғанда, эллипс пішінді ерекше тұтқалы ерте сарматтық темір қанжарлар мен қылыштардың Орталық Азиядан таралу феноменіне арналған. Мұндай қарудың ең үлкен концентрациясы Тянь-Шань маңы аймағында тіркеледі, бірақ кейбір үлгілер Солтүстік Бактрияда (Тәжікстанның оңтүстігіндегі) және Ферғана маңында кездеседі. Осындай тұтқалары бар қанжарлар мен қылыштар ертедегі сарматтық мәдениеттің көне дәуірінде Оңтүстік Орал маңында және Оралдың арғы бетінде, сондай-ақ скифтік нысандары Саян-Алтайдың аумағында кездеседі. Осындай тұтқалары бар пышақ қаруының хронологиясы IV-III ғасырларға сәйкес келеді және оның үлгілері белгілі ескерткіштерге арналған сенімді хронологиялық көрсеткіш болып табылады.
\end{abstract}

Кілт сөздер: ерте көшпелілер; қарулану; қанжарлар мен қылыштар; эллипстәрізді тұтқалар.

\section{Кинжалы и мечи раннесарматского облика с эллипсоидными рукоятями в Средней Азии}

\section{Иванов Сергей Сергеевич}

кандидат исторических наук, доцент Кыргызского национального университета имени Ж. Баласагына. Кыргызская Республика, 720033, г. Бишкек, ул. Фрунзе, 547. E-mail: sergioiv@mail.ru.

Аннотация. Статья посвящена анализу особого типа рукоятей железных кинжалов и мечей раннесарматского облика из Средней Азии. Наибольшая концентрация подобного клинкового оружия фриксируется в Притяньшанье, но отдельно похожие образцы также есть в Северной Бактрии (Южный Таджикистан) и Приферганье. Кинжалы и мечи с аналогичными рукоятями отмечаются в древностях раннесарматской культуры в Южном Приуралье и Зауралье, а также на территории культур скифского облика Саяно-Алтая. Хронология клинкового оружия с подобными рукоятями укладывается в IV-III вв. и является надежным хронологическим индикатором для памятников, из которых известны его образцы.

Ключевые слова: ранние кочевники; вооружение; кинжалы и мечи; эллипсоидные рукояти. 
әОЖ/ УДК 902.22

\title{
Кинжалы и мечи раннесарматского облика с эллипсоидными рукоятями в Средней Азии
}

\author{
Иванов C.C.
}

Кинжалы играли значительную роль в комплексе вооружения среднеазиатских кочевников, занимая ключевую позицию среди средств ведения ближнего боя. К настоящему времени здесь известно значительное количество образцов клинкового оружия, относящегося к I тыс. до н.э., но наше внимание привлекло несколько кинжалов и мечей, имеющих очень специфическую деталь - рукоять, которая плавно сужается к навершию и перекрестию, приобретая эллипсоидную форму. Хотя в некоторых случаях она сильнее сужается только к навершию, отчего ее форма приближается к ассиметрично эллипсоидной. Примечательно также то, что данный тип рукояти в Средней Азии фриксируется только на железных кинжалах и мечах раннесарматского типа. При подробном рассмотрении оказалось, что подобные эллипсоидные рукояти существовали в достаточно ограниченный хронологический период, что позволяет уточнить хронологию некоторых кинжалов, а также других предметов им сопутствовавших и, соответственно, археологических комплексов, где они были обнаружены.

В Средней Азии находки клинкового оружия с эллипсоидной рукоятью отмечены в Притяньшанье, Северной Бактрии и Приферганье. Большая часть из них происходит из Притяньшанья, где они отмечены в ряде захоронений в могильниках Кетмень-Тюбинской долины на Западном Тянь-Шане, а также в курганах Иссык и Беркаринского могильника в Семиречье. Единичные экземпляры также были найдены в так называемом храме Окса (Тахти-Сангин) в северной части Бактрии (Южный Таджикистан) и в кладе из Исфраринской долины в Прифрерганье.

В Кетмень-Тюбинской долине известны три кинжала с интересующим нас типом рукояти. Первый из них происходит из к.6 мог.Акчий-Карасу (Ташбаева 2011, С.68-69, рис.60:1). Он имеет прямые навершие и перекрестие, клинок обломан практически у самого основания. Несмотря на то, что рукоять сохранилась частично, ее форма определяется достаточно хорошо. Помимо кинжала в данном погребении были найдены золотые и бронзовые бляшки, обернутые золотой фрольгой, которые близки по стилю и оформлению к найденным в кургане Иссык, поэтому вполне надежно могут быть датированы IV в. до н.э. Также в этом же кургане было обнаружено фрагментарно сохранившееся зеркало в виде простого диска, без рукояти. Зеркала подобного типа по целому ряду аналогий может быть датировано в пределах IV-II вв. до н.э. (Мошкова 1963, C.41, табл. 27: 1-5; Иванов 2016, С.76). Наличие подобных предметов в данном захоронении дало основания для датировки кинжала из него IV-III вв. до н.э. (Ташбаева 2011, С.87, рис. 80).

Второй кинжал был обнаружен в к.2 мог.Боз-Тектир (Ташбаева 2011, С.6869 , рис. 60.3). Он имеет слабоизогнутое навершие, плоскую эллипсоидную рукоять и прямое перекрестье с плавно утончающимися краями. Клинок у него также не сохранился. Детальная датировка этого захоронения несколько затруднена, поскольку здесь кроме кинжала были зафиксированы только обломки лепной керамической чаши, характерной для V - перв.пол. II вв. до н.э. 
Помимо двух описанных кинжалов в к.7 мог.Джал-Арык II была найдена рукоять железного кинжала. У нее обломаны перекрестье и часть прямого навершия (Кожомбердиев 1977, рис.3; Ташбаева 2011, С.68-69, рис.60:2). Судя по эллипсоидной рукояти и облику навершия, он мог иметь прямое либо дуговидное перекрестье. Помимо рукояти кинжала в данном кургане были найдены десять черешковых трехлопастных наконечников стрел, девять из которых бронзовые и один железный, а также железные поясная обойма с прорезью и круглая бляха, инкрустированные маленькими схематическими бронзовыми фригурками птиц. По сочетанию наконечников стрел, особенно по наличию в нем кованного железного, колчанный набор из этого кургана может датироваться концом IV-III вв. до н.э., чему не противоречит и поясная обойма, дающая дату IV-III вв. до н.э. (Иванов 2009, С.70-71).

В Семиречье, как упоминалось выше, кинжалы и мечи с эллипсоидной рукоятью известны из двух пунктов - Иссыка и Берккары. В кургане Иссык ею обладают найденные там кинжал и длинный всаднический меч. Кинжал имеет почковидное перекрестье, круглую в разрезе рукоять, обвитую золотой проволокой и обтянутое золотой фольгой зооморфное навершие в виде обращенных друг к другу головок грифонов золота (Акишев 1978, С.29-30, табл. 40). У меча слабоизогнутое дуговидное навершие, узкое сломанное под углом перекрестие со скругленными концами, что в свое время позволило определить его форму как «узкое бабочковидное», но оно, скорее, угловато-брусковидное. Круглая в сечении эллипсоидная рукоять также была обвита тонкой золотой проволокой, а навершие и перекрестье украшены мелкими фигурными пластинками из золота (Акишев 1978, С.30, табл. 43). Что же касается датировки оружия из Иссыка, то А.К. Акишев, анализируя материалы из данного кургана, привел достаточно доказательств, что кинжал более связан с местной «скифской» традицией, в то время как меч находит ближайшие аналогии в сарматском мире Поволжья и Южного Приуралья. И это, наряду с другими предметами погребального инвентаря, хорошо обосновывало дату IV - начала III вв. до н.э. для этого памятника (Акишев 1984, С.5), которая в настоящее время мало у кого вызывает сомнения. Впрочем, сочетание в элитарном комплексе, где присутствовали только передовые инновации, кинжала, несущего отпечаток уходящей оружейной традиции, и меча, в котором воплотились все «модные» тенденции того времени, может говорить о возможной его датировке первой половиной IV столетия до н.э.

От меча или кинжала из к.270 Берккаринского могильника сохранилась только рукоять. Она имеет слабоизогнутое, почти прямое навершие, а также прямое, несколько утончающееся к концам перекрестие. В целом, данная рукоять очень близка рукояти кинжала из Боз-Тектира, отличаясь от последней только едва заметной изогнутостью перекрестья. Вместе с рукоятью в погребении был найден железный черешковый трехгранный наконечник стрелы, что в свое время во многом стало основанием для датировки кургана 270 III-II вв. до н.э. (Бабанская 1956, C.197, 204-205, табл. VIII, 1), с чем в настоящий момент нельзя полностью согласиться. Как показал Б.А. Литвинский, мелкие железные черешковые наконечники стрел достаточно рано появляются в среднеазиатских комплексах - уже в IV-III вв. до н.э. А учитывая, что экземпляр из Берккары имеет сводчатую головку - достаточно архаичный признак, то его датировка указанным временем не вызывает особых сомнений (Литвинский 2001, С.86-91, 93-95). А находка в этом же кургане нескольких лепных керамических сосудов сакского типа только подтверждает его датировку в рамках в IVIII вв. до н.э. 

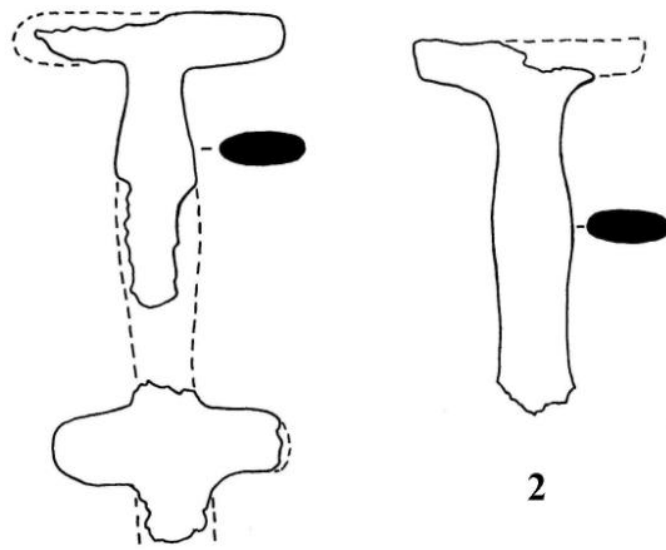

2

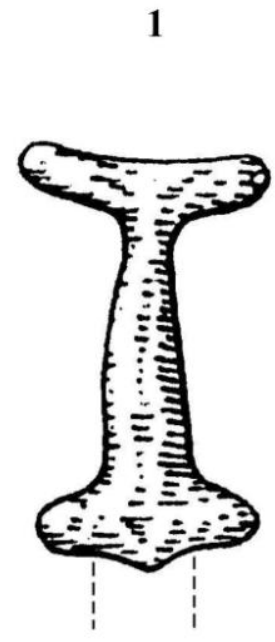

5

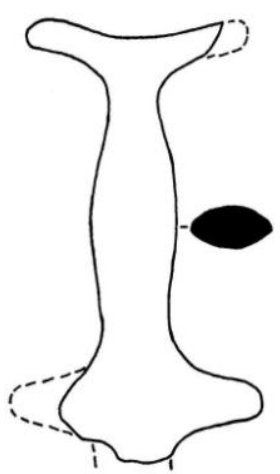

3

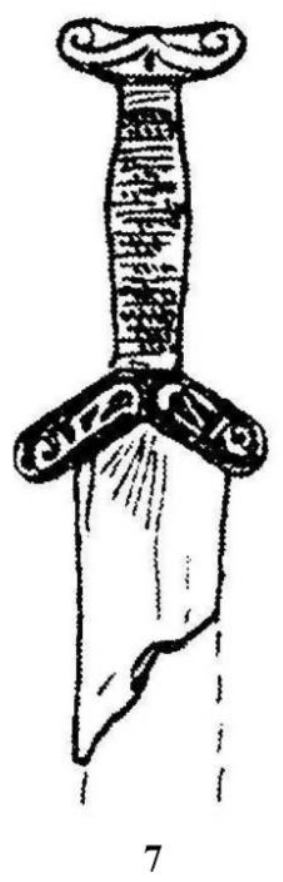

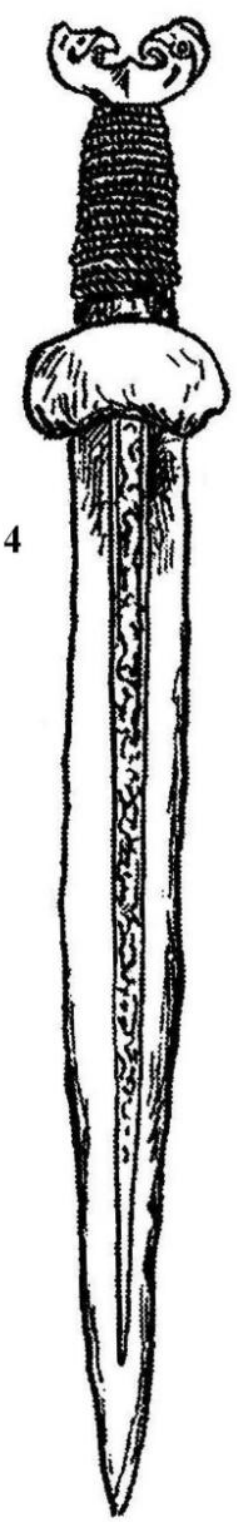

Рисунок 1. Кинжалы и мечи раннесарматского облика с эллипсоидной рукоятью из Средней Азии (даны не в масштабе). 1-3 - Кетмень-Тюбинская долина (Западный Тянь-Шань); 4, 7 - Иссык (Семиречье); 5 - Берккара (Семиречье); 6 - храм Окса (Тахти-Сангин) (Южный Таджикистан).

Кинжал из эллинистического храма Окса (Тахти-Сангин) в Южном Таджикистане имеет рожковидное навершие, широкую эллипсоидную рукоять и «сломанное» под углом брусковидное перекрестие. Он сохранился почти полностью, кроме кончика лезвия. На основе сарматских аналогий Б.А. Литвинский датирует его концом IV-III вв. до н.э., но чуть ниже он пишет, что кинжалы из храма Окса «в своей массе относятся к периоду едва ли более раннему, чем III-I вв. до н.э.» (Литвинский 2001, С.207, 244-245, 248, рис. 58:5). Из чего можно сделать вывод, что он более склоняется к датировке этого кинжала III в. до н.э. 


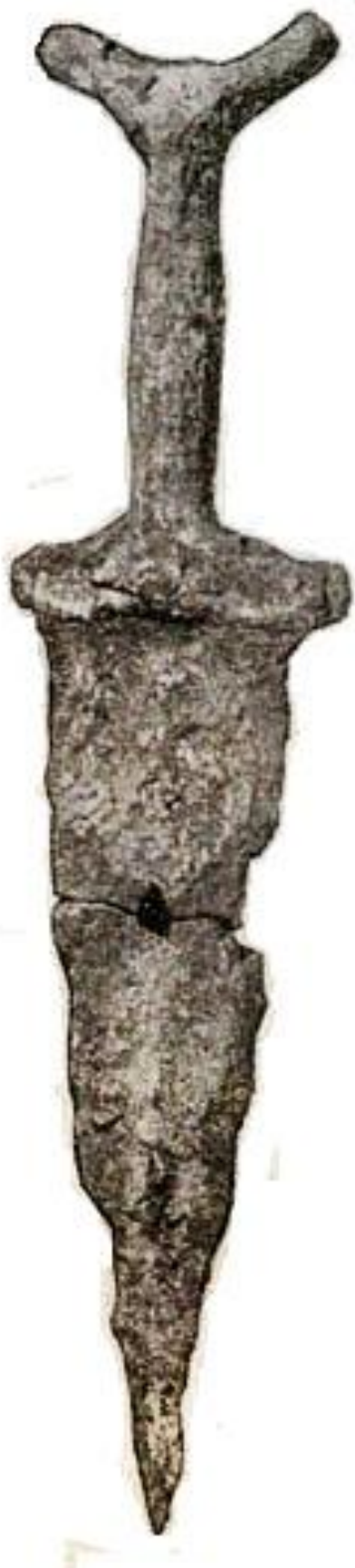

Рисунок 2. Кинжал раннесарматского облика эллипсоидной рукоятью из Исфраринской долины (Приферганье)
Кинжал из Иссраринской долины в южной части Приферганья обладает навершием, близким по форме к «рожковому», прямым перекрестьем и широким треугольным клинком. Он был найден в составе клада, в котором ему сопутствовали бронзовые скульптурные головки баранов в скифосакской зверином стиле, что достаточно обоснованно позволило отнести его к IV-III вв. до н.э. (Негматов 1987, С.53-54, рис.3).

Итак, из обзора известных в Центральной Азии кинжалов и мечей с интересующим нас типом рукояти, становится очевидным, что они принадлежат к следующим основным типам клинкового оружия:

1. с прямыми перекрестием и навершием (Акчий-Карасу, возможно, Джал-Арык II)

2. с прямым перекрестием и дуговидным навершием (БозТектир, Берккара, Исфраринская долина)

3. со «сломанным» под углом перекрестием и рожковым или дуговидным навершием (храм Окса, Иссык)

4. с почковидным перекрестьем и зооморфным навершием в виде пары головок грифонов (Иссык).

И если первые три типа можно отнести к оружию так называемого «сарматского» облика, то последний кинжал из Иссыка выпадает из общей массы клинкового оружия с эллипсоидными рукоятями и демонстрирует поздний образец развития местного вооружения, так как имеет аналогии своему декору только в нашем регионе и Южной Сибири, Ордосе, т.е. исключительно в восточной части скифо-сибирского мира (Акишев 1978, С.34-35).

Для уточнения хронологии рассматриваемых типов кинжалов предлагаю обратиться к аналогиям, в первую очередь - к собственно раннесарматским. Так, железные кинжалы с прямым брусковидным навершием и перекрестьем были достаточно широко распространены в кочевом мире в эпоху ранних ко- 
чевников. В Восточной Европе они встречаются в погребениях раннесарматской культуры Южного Урала и Поволжья и, по данным последних исследований, датируются IV - началом III вв. до н.э. (Смирнов 1961, рис.7:12; Васильев 2001, С.171-172, рис.2; Клепиков 2002, С.28-29, рис.2:13-16). Вотивные и полноразмерные кинжалы рассматриваемого типа известны и в Южной Сибири в пределах IV-II вв. до н.э. (Кубарев 1981, С.30-42, рис. 2.13, 8.4; Могильников 1997, С.46, рис.47.4; Шульга 2007, С.144, рис. 2:20, 211). Исходя из этого, данный тип клинкового оружия можно хронологически расположить в пределах IVIII вв. до н.э.

Что же касается кинжалов и мечей раннесарматского типа - с серповидным или рожковым навершием и прямым перекрестьем, то они были очень широко распространены от Северного Причерноморья до Южной Сибири. В нашем регионе они известны в Восточном Прикаспии в сарматоидных памятниках Устюрта и Мангышлака, где они датируются в пределах IV-II вв. до н.э. (Степная полоса 1992, С.126-127, табл. 50.1-2). Сходный короткий меч, но имевший иное оформление рукояти, известен из Согда, где он был датирован второй половиной IV в. до н.э. (Обельченко 1978, С.116-117, рис. 1.2). Кроме того, единичные находки таких кинжалов известны в Центральном и Северном Казахстане, где они были датированы концом V-III вв. до н.э. (Кадырбаев 1968, С.25-30, рис. 1.30; Хабдулина 1994, С.56, табл. 52, 11). Отдельные находки сходных подобных кинжалов известны также в Западной Сибири, где они датируются и III-ІІ вв. до н.э. (Степная полоса азиатской части СССР 1992, С.472, табл. 122:44).

Основная масса подобных мечей и кинжалов происходит из сарматских памятников Южного Урала и Поволжья, где они существовали, в основном, в пределах конца IV-II вв. до н.э. (Мошкова 1963, С.34, табл.18-19; Пшеничнюк 1983, С.107-108, табл. X.8, XI.7-8, XXIII.14-16). Правда, недавние исследования показали, что кинжалы и мечи раннесарматского облика бытовали в Восточной Европе и в первой половине І в. до н.э. (Васильев 2001, С.172, рис. 2; Федоров 2001, С.182-186; Клепиков 2002, С.29-30, рис. 2.17-32). Это подтверждается и находками с Северного Причерноморья, где подавляющая часть клинкового оружия с прямым перекрестием и рожковым навершием известна из памятников именно II-І вв. до н.э. (Симоненко 2009, С.13-25).

По-видимому, похожая ситуация со временем их существования была и в Средней Азии, где в кочевнических памятниках Бактрии были обнаружены кинжалы типично раннесарматского типа, относящиеся к концу II-I вв. до н.э. (Мандельштам 1966, C.110-111, табл.XL; Литвинский 2001, С.246, табл.61:3-4). Исходя из изложенного, данный тип, на наш взгляд, в нашем регионе можно датировать пределах IV-I вв. до н.э.

Клинковое оружие со «сломанным» под углом перекрестием и рожковым или дуговидным навершием опять-таки более всего находит аналогии в раннесарматских древностях, где они известны в относительно ограниченном количестве, что позволяет говорить об их сравнительно недолгом бытовании в комплексе вооружения ранних кочевников - в пределах IV в. до н.э. (Мошкова 1963, табл.18:11; Клепиков 2002, С.27-28, рис.2:5). Хотя, как упоминалось выше, Б.А. Литвинский склонен датировать кинжал из храма Окса в Северной Бактрии III в. до н.э.

Что же касается последнего типа - с почковидным перекрестьем и зооморфным навершием в виде пары головок грифонов, то он является единич-

\footnotetext{
${ }^{1}$ П.И. Шульга с осторожностью высказался о наличии кинжалов этого типа в лесостепном Алтае, поскольку во всех приводимых случаях перекрестие сильно разрушено (2007, С.144).
} 
ной находкой этого рода и его дата хорошо определяется общей датой кургана Иссык.

Таким образом, существование кинжалов и мечей с эллипсоидной рукоятью в целом укладывается в хронлогические границы c IV по I вв. до н.э., хотя большая часть рассматриваемого оружия относится к IV-III вв. до н.э. Сомнения вызывают лишь кинжалы и мечи «прохоровского» типа - с прямым перекрестьем и дуговидным или рожковым навершием, которые также существовали в нашем регионе и в II-I вв. до н.э.

Но, как оказалось, эллипсоидные рукояти существовали не только в Средней Азии, но и на более обширных территориях - Поволжье, Приуралье, Зауралье и Лесостепном, и Горном Алтае, и Туве.

Они известны на раннесарматском клинковом оружии IV-III вв. до н.э. (Смирнов 1961, С.25-27, рис.5:5; 7.11; Мошкова 1963, табл.18:9, 11; 1974, С.2526, рис.5:9), но их находки единичны и ограничиваются только Южным Приуральем и прилегающей частью Зауралья. Ряд кинжалов с эллипсоидными рукоятями отмечены также на территории каменской культуры в Лесостепном Алтае, где они датируются к IV - началом III вв. до н.э., с возможным заходом также в V в. до н.э. (Могильников 1997, С.43-46, рис. 37.3, 5, 6, 8; 39.5; Шульга 2007, С.147, рис.2:10). Отдельные их экземпляры известны из соседних Горного Алтая (Кочеев 1995, С.132, рис. 1.2) и Тувы (Семенов 2003, С.28, табл. 32. 23). И, таким образом, получается, что кинжалы и мечи с эллипсоидной рукоятью бытовали только в IV-III вв. до н.э.

Примечательно также то, что рукояти некоторых скифских кинжалов и мечей из Северного Причерноморья имеют очень сходную форму рукоятей, притом, они датируются IV-первой половиной III вв. до н.э. (Мелюкова 1964, C.5154, табл.18:3, 9, 11), когда скифское клинковое вооружение переживало сложный период трансформации: к примеру, перекрестья у всех упомянутых экземпляров узкие бабочковидные или ложно-треугольные, что, видимо, отражало стадиальные изменения в развитии кинжалов и мечей степного пояса Евразии. Но, несмотря на то, что причерноморские образцы достаточно близки рукоятям на клинковом оружии раннесарматского облика, они все же обладают некоторыми отличиями - в частности они более уплощенные в разрезе, что указывает, скорее, на случайное сходство, чем на прямую взаимосвязь.

Итак, получается, что территориально эллипсоидные рукояти были достаточно широко распространены в кочевом мире, притом, не только в Средней Азии: они известны от Южного Приуралья до Саяно-Алтая.

На то, что рукояти эллипсоидного облика были распространены именно в IV-III вв. до н.э. указывает еще один косвенный признак. Дело в том, что рукояти кинжалов и мечей так называемого раннесарматского типа морфологически продолжали оружейные традиции более раннего времени - VII-V вв. до н.э. То есть, в отличие от кинжалов и мечей II-I вв. до н.э., которые часто имели очень узкие, иногда почти штыревидные рукояти, снабженные деревянными накладками или же обмоткой (Симоненко 2009, С.14-16), кинжалы более раннего времени имели широкую, овальную, прямоугольную, реже круглую в сечении рукоять. Эллипсоидные рукояти вряд ли имели деревянные или иные накладки, поскольку они овальные и круглые в сечении. Хотя, они могли иметь обмотку из мягких материалов (ткань, полоски кожи и др.), на что косвенно указывает декорация рукоятей меча и кинжала золотой проволокой из кургана Иссык. Поэтому в данном случае они также продолжают традиции более раннего периода, что свидетельствует в пользу их отнесения к IV-III вв. до н.э. 
Впрочем, следует отметить, что известны более поздние реминисценции эллипсоидных рукоятей, но это крайне редкое явление. Притом есть одно существенное отличие - рукояти поздних мечей плоские (Смелы и Большая Белозерка в Северном Причерноморье), ранние же никогда не бывают плоскими, как было показано выше. Это опять же говорит о том, что поздние образцы имели деревянные или иные накладки и генетически, скорее всего, не связаны с ранними эллипсоидными рукоятями, а представляют собой единичное, случайное явление, выражающееся лишь чисто во внешнем сходстве. К тому же, между указанными мечами из Причерноморья хронологический разрыв несколько столетий, что опять-таки говорит о случайности, чем о совпадении (Симоненко 2009, С.17-18, 28, рис. 4:4; 10).

Выяснив каким временем датируются эллипсоидные рукояти кинжалов и мечей, мы можем теперь не только разграничить более ранние и более поздние группы железных кинжалов, но уточнить хронологическую позицию некоторых археологических комплексов, а также других предметов, происходящих из них. И, таким образом, мы получили более или менее надежный хронологический маркер, который в будущем может существенно помочь датировать новые памятники как в Средней Азии, так и сопредельных регионах.

Но, с другой стороны, не совсем понятны происхождение и пути распространения клинкового оружия с эллипсоидными рукоятями в среде евразийских кочевников. Ясно лишь то, что они были привнесены в наш регион извне вместе с раннесарматскими формами кинжалов и мечей, но откуда?

Обращает на себя внимание, что основными районами распространения кинжалов и мечей с рукоятями этого типа были Притяньшанье и Лесостепной Алтай. Причем, в последнем регионе подавляющая их часть была найдена на территории распространения каменской культуры, которая была тесно связана культурно и генетически с сакской культурой Притяньшанья. Учитывая, что основная территория фрормирования клинкового оружия раннесарматского облика находилась гораздо севернее Притяньшанья, то вполне обоснованно будет предполагать, что они проникают туда именно с Алтая. Это отчасти подтверждается также тем, что на западе Средней Азии кинжалы и мечи с подобными рукоятями практически не известны, и их изображение зафиксировано только один раз на каменной статую типа Байте на плато Мангышлак (Ольховский 2005, илл.151). А принимая во внимание их единичность в Приферганье и Северной Бактрии, не исключено, что они туда попадают в результате контактов с Притяньшаньем. В то же время примечательно то, что в ареале раннесарматской культуры кинжалы и мечи с эллипсоидными рукоятями известны только в восточной его части и то в очень небольшом количестве, что скорее указывает на их восточное происхождение. Поэтому, вероятнее всего, что они формируются на Алтае или же, как максимум, в пространстве от последнего до Зауралья и прилегающей части Южного Приуралья.

Получается, что Средняя Азия была вторичным регионом распространения клинкового оружия с эллипсоидными рукоятями, где основным районом применения мечей и кинжалов с данным признаком было Притяньшанье. Именно отсюда, по-видимому, оно могло в результате культурных и иных контактов проникать в сопредельные области региона.

Итак, кинжалы и мечи с эллипсоидными рукоятями существовали в степях Евразии сравнительно ограниченный период - в IV-III вв. до н.э., в результате чего они выступают надежным хронологическим индикатором для погребальных и поселенческих памятников как для Средней Азии, так и для других регионов, где оружие с подобного типа рукоятями было обнаружено. 


\section{Әдебиеттер тізімі/ Список литературы}

1. Акишев К.А. Курган Иссык. Искусство саков Казахстана. - М.: Искусство, 1978. - 132 с.

2. Акишев А.К. Искусство и мифология саков. Алма-Ата: Наука, 1984. - 176 с.

3. Бабанская Г.Г. Берккаринский могильник // Труды института истории, археологии и этнографии АН КазССР. - Т. 1. - Алма-Ата: Изд-во АН Каз. ССР, 1956. - С. 189-206.

4. Васильев В.Н. К хронологии раннепрохоровского клинкового оружия и проблеме III в. до н.э. // Материалы по археологии Волго-Донских степей. - Волгоград: ВГУ, 2001. - С.169-179.

5. Иванов С.С. Боевые пояса ранних кочевников Центральной Азии // Материалы и исследования по археологии Кыргызстана. Вып. 4. - Бишкек: Илим, 2009. - С. 66-75.

6. Иванов С.С. К проблеме культурного разрыва на рубеже сакского и усуньского периодов в Притяньшанье // Stratum plus. Третий до ... Потерянное столетие. - 2016. - № 3. - C. 67-87.

7. Кадырбаев М.К. Некоторые итоги и перспективы изучения археологии раннежелезного века Казахстана // Новое в археологии Казахстана. - Алма-Ата: Наука, 1968. - С. 21-36.

8. Клепиков В.М. Сарматы Нижнего Поволжья в IV-III вв. до н.э. - Волгоград: Изд-во ВГУ, 2002. $216 \mathrm{c}$.

9. Кожомбердиев И.К. Основные этапы истории культуры Кетмень-Тюбе // Кетмень-Тюбе. Фрунзе: Илим, 1977. - С. 9-24.

10. Кочеев В.А. Два кинжала из Горного Алтая // Известия лаборатории археологии. №1. ГорноАлтайск: ГАГУ, 1995. - С. 83-84.

11. Кубарев В.Д. Кинжалы из Горного Алтая // Военное дело древних племен Сибири и Центральной Азии. - Новосибирск: Наука, 1981. - С. 29-54.

12. Литвинский Б.А. Храм Окса в Бактрии. - Т.2. Бактрийское вооружение в древневосточном и греческом контексте. - М.: Восточная литература, 2001. - 530 с.

13. Мандельштам А.М. Кочевники на пути в Индию. - М.-Л.: Наука, 1966. - 232 с.

14. Мелюкова А.И. Вооружение скифов. САИ. Вып. Д1-4. - М.: Наука, 1964. - 91 с.

15. Могильников В.А. Население Верхнего Приобья в середине - второй половине I тыс. до н.э. - М., 1997. - 195 C.

16. Мошкова М.Г. Памятники прохоровской культуры. САИ. Вып. Д1-10. - М.: Изд-во АН СССР, 1963. -55 c.

17. Мошкова М.Г. Происхождение раннесарматской (прохоровской) культуры. - М.: Наука, 1974. - 52 с.

18. Негматов Н.Н. Бронзовые скульптуры из Исфраринской долины и их историко-культурное значение // Скифо-сибирский мир. Искусство и идеология. - Новосибирск: Наука, 1987. - С. 49-55.

19. Обельченко О.В. Мечи и кинжалы из курганов Согда // Советская археология. - № 4. - 1978. C.115-127.

20. Ольховский В.С. Монументальная скульптура населения западной части Евразийских степей эпохи раннего железа. - М.: Наука, 2005. - 299 с.

21. Пшеничнюк А.Х. Культура ранних кочевников Южного Урала. - М.: Наука, 1983. - 200 с.

22. Симоненко А.В. Сарматские мечи и кинжалы на территории Северного Причерноморья // Вооружение скифов и сарматов. - Киев: Наукова думка, 1984. - С. 129-147.

23. Симоненко А.В. Сарматские всадники Северного Причерноморья. СПб: СПбГУ, 2009. - 328 с.

24. Смирнов К.Ф. Вооружение савроматов. Материалы и исследования по археологии СССР. № 101. - М.: Изд-во АН СССР, 1961. - 168 с.

25. Степная полоса Азиатской части СССР в скифо-сарматское время. - М.: Наука, 1992. - 494 с. 26. Ташбаева К.И. Культура ранних кочевников Тянь-Шаня и Алая. - Бишкек: Илим, 2011. - 274 с. 27. Федоров В.Ф. Клинковое оружие и колчанные наборы IV-III вв. до н.э. (о времени появления на Южном Урале мечей и кинжалов прохоровского типа) // Материалы по археологии ВолгоДонских степей. - Волгоград: ВГУ, 2001. - С. 180-197.

28. Хабдулина М.К. Степное Приишимье в эпоху раннего железа. - Алматы: Ракурс, 1994. - 170 с. 29. Шульга П.И. Вооружение на Алтае в VI-III вВ. до н.э. // Вооружение сарматов: региональная типология и хронология. - Челябинск: Изд-во ЮУрГУ, 2007. - С.142-156.

\section{References}

Akishev 1978 - Akishev, KA 1978, Kurgan Issyk. Iskusstvo sakov Kazahstana, Moscow, 132 p. (Akishev, KA 1978, Issyk Barrow. The art of Saka in Kazakhstan, Moscow, 132 p). (in Rus).

Akishev 1984 - Akishev, AK 1984, Iskusstvo i mifologiya sakov, Alma-Ata, 176 p. (Akishev, AK 1984, Art and mythology of Sakas, Alma-Ata, 176 p). (in Rus).

Babanskaya 1956 - Babanskaya, GG 1956, Berkkarinskiy mogil'nik, Trudy instituta istorii, arheologii $i$ etnografii AN KazSSR, T.1, Alma-Ata, P.189-206. (Babanskaya, GG 1956, Baccarini burial ground, Proceedings of the Institute of history, archeology and Ethnography of the Kazakh SSR, T.1, Alma-Ata, P.189-206). (in Rus). 
Fedorov 2001 - Fedorov, VF 2001, Klinkovoe oruzhie i kolchannye nabory IV-III vv. do n.e. (o vremeni poyavleniya na Yuzhnom Urale mechej i kinzhalov prokhorovskogo tipa), Materialy po arkheologii Volgo-Donskikh stepey, Volgograd, P.180-197. (Fedorov, VF 2001, Bladed weapon and colchane sets the IV-III centuries BC (the time of occurrence in the southern Urals swords and daggers of the Prokhorovka type), Materials on archeology of Volga-Don steppes, Volgograd, P.180-197). (in Rus).

Ivanov 2009 - Ivanov, SS 2009, Boevye poyasa rannikh kochevnikov Tsentral'noy Azii, Materialy $i$ issledovaniya po arkheologii Kyrgyzstana, Vyp.4, Bishkek, P.66-75. (Ivanov, SS 2009, Battle belts of early nomads of Central Asia, Materials and researches on archeology of Kyrgyzstan, Issue 4, Bishkek, P.66-75). (in Rus).

Ivanov 2016 - Ivanov, SS 2016, K probleme kul'turnogo razryva na rubezhe sakskogo i usun'skogo periodov v Prityan'shan'e, Stratum plus. Tretiy do ... Poteryannoe stoletie, №3, P.67-87. (Ivanov, SS 2016, the problem of cultural divide at the turn of the Saka and wusun periods in Pritenenie, Stratum plus. Third to ... The lost century, №3, P.67-87). (in Rus).

Kadyrbaev 1968 - Kadyrbaev, MK 1968, Nekotorye itogi i perspektivy izucheniya arkheologii rannezheleznogo veka Kazakhstana, Novoe $v$ arkheologii Kazakhstana, Alma-Ata, P.21-36. (Kadyrbaev, MK 1968, Some results and prospects of studying the archaeology of early iron age of Kazakhstan, New in archaeology of Kazakhstan, Alma-Ata, P.21-36). (in Rus).

Khabdulina 1994 - Khabdulina, MK 1994, Stepnoe Priishim'e v ehpokhu rannego zheleza, Almaty, 170 p. (Khabdulina, MK 1994, Priishimje steppe in the Early Iron age, Almaty, 170 p). (in Rus).

Klepikov 2002 - Klepikov, VM 2002, Sarmaty Nizhnego Povolzh'ya v IV-III vv. do n.e., Volgograd, 216 p. (Klepikov, VM 2002, Sarmatians of the Lower Volga region in IV-III centuries BC, Volgograd, 216 p.). (in Rus).

Kozhomberdiev 1977 - Kozhomberdiev, IK 1977, Osnovnye ehtapy istorii kul'tury Ketmen'-Tyube, Ketmen'-Tyube, Frunze, P.9-24. (Kozhomberdiev, IK 1977, the Main stages of the cultural history of the Ketmen-Tyube, Ketmen'-Tyube, Frunze, P.9-24). (in Rus).

Kocheev 1995 - Kocheev, VA 1995, Dva kinzhala iz Gornogo Altaya, Izvestiya laboratorii arheologii, №1, Gorno-Altaysk, P.83-84. (Kocheev, VA 1995 Two daggers of Mountain Altai, Proceedings of the laboratory of archaeology, №1, Gorno-Altaysk, P.83-84). (in Rus).

Kubarev 1981 - Kubarev, VD 1981, Kinzhaly iz Gornogo Altaya, Voennoe delo drevnih plemen Sibiri $i$ Central'noy Azii, Novosibirsk, P.29-54. (Kubarev, VD 1981, Daggers from the Altai Mountains,/ Military Affairs of ancient tribes of Siberia and Central Asia, Novosibirsk, P.29-54). (in Rus).

Litvinskij 2001 - Litvinskij, BA 2001, Khram Oksa v Baktrii, T.2. Baktriyskoe vooruzhenie v drevnevostochnom i grecheskom kontekste, Moscow, 530 p. (Litvinskij, BA 2001, Temple of the Oxus in Bactria, T. 2. Bactrian armament in the ancient Eastern and Greek context, Moscow, 530 p). (in Rus).

Mandel'shtam 1966 - Mandel'shtam, AM 1966, Kochevniki na puti v Indiyu, Moscow-Leningrad, 232 p. (Mandel'shtam, AM 1966, Nomads on the way to India, Moscow-Leningrad, 232 p). (in Rus).

Melyukova 1964 - Melyukova, Al 1964, Vooruzhenie skifov, SAl, Vyp.D1-4, Moscow, 91 p. (Melyukova, Al 1964, Weapons of the Scythians, SAl, Vyp.D1-4, Moscow, 91 p). (in Rus).

Mogil'nikov 1997 - Mogil'nikov, VA 1997, Naselenie Verhnego Priob'ya v seredine - vtoroy polovine I tys. do n.e., Moscow, 195 p. (Mogil'nikov, VA 1997, the Population of the Upper Ob region in the middle-second half of the I Millennium BC-M, Moscow, 195 p).(in Rus).

Moshkova 1963 - Moshkova, MG 1963, Pamyatniki prokhorovskoy kul'tury, SAl, Vyp.D1-10, Moscow, 55 p. (Moshkova, MG 1963, Monuments of culture Prokhorov, SAl, Vyp.D1-10, Moscow, 55 p).(in Rus).

Moshkova 1974 - Moshkova, MG 1974, Proishozhdenie rannesarmatskoy (prohorovskoy) kul'tury, Moscow, 52 p. (Moshkova, MG 1974, Origins rennermalm (Prokhorov) culture, Moscow, 52 p).(in Rus).

Negmatov 1987 - Negmatov, NN 1987, Bronzovye skul'ptury iz Isfarinskoy doliny i ikh istorikokul'turnoe znachenie, Skifo-sibirskij mir. Iskusstvo i ideologiya, Novosibirsk, P.49-55. (Negmatov, NN 1987, Bronze sculpture of Isfarinskiy valleys and their historical and cultural value, The Scythian-Siberian world. Art and ideology, Novosibirsk, P.49-55). (in Rus).

Obel'chenko 1978 - Obel'chenko, OV 1978, Mechi i kinzhaly iz kurganov Sogda, Sovetskaya arkheologiya, №4, P.115-127. (Obel'chenko, OV 1978, Swords and daggers from the mounds of Sogda, Soviet archaeology, №4, P.115-127). (in Rus).

Ol'khovskij 2005 - Ol'khovskij, VS 2005, Monumental'naya skul'ptura naseleniya zapadnoy chasti Evraziyskikh stepey ehpokhi rannego zheleza, Moscow, 299 p. (Ol'khovskij, VS 2005, Monumental sculpture of the population of the Western part of the Eurasian States of the early iron age, Moscow, 299 p). (in Rus).

Pshenichnyuk 1983 - Pshenichnyuk, AKh 1983, Kul'tura rannikh kochevnikov Yuzhnogo Urala, Moscow, 200 p. (Pshenichnyuk, AKh 1983, The Culture of the early nomads of the Southern Urals, Moscow, 200 p). (in Rus).

Shul'ga 2007 - Shul'ga, PI 2007, Vooruzhenie na Altae v VI-III vv. do n.e., Vooruzhenie sarmatov: regional'naya tipologiya i khronologiya, Chelyabinsk, P.142-156. (Shul'ga, PI 2007, Armament on Altai in VI-III centuries B.C., Armament of Sarmatians: regional typology and chronology, Chelyabinsk, P.142-156). (in Rus). 
Simonenko 1984 - Simonenko, AV 1984, Sarmatskie mechi i kinzhaly na territorii Severnogo Prichernomor'ya, Vooruzhenie skifov i sarmatov, Kiev, P.129-147. (Simonenko, AV 1984, Sarmatian swords and daggers on the territory of the Northern black sea region, The Weaponry of the Scythians and Sarmatians, Kiev, P.129-147). (in Rus).

Simonenko 2009 - Simonenko AV 2009, Sarmatskie vsadniki Severnogo Prichernomor'ya, Saint Petersburg, 328 p. (Simonenko AV 2009, Sarmatian riders of the Northern Black sea region, Saint Petersburg, 328 p). (in Rus).

Smirnov 1961 - Smirnov, KF 1961, Vooruzhenie savromatov. Materialy $i$ issledovaniya po arkheologii SSSR, №101, Moscow, 168 p. (Smirnov, KF 1961, Weapons savromats. Materials and research on archaeology of the USSR, №101, Moscow, 168 p). (in Rus).

Stepnaya polosa Aziatskoj 1992 - Stepnaya polosa Aziatskoj chasti SSSR v skifo-sarmatskoe vremya, 1992, Moscow, 494 p. (Steppe band of the Asian part of the USSR in the Scythian-Sarmatian time, 1992, Moscow, 494 p). (in Rus).

Tashbaeva 2011 - Tashbaeva, KI 2011, Kul'tura rannih kochevnikov Tian'-Shanya i Alaya, Bishkek, 274 p. (Tashbaeva, KI 2011, Culture of early nomads Tien Shan and Alai, Bishkek, 274 p). (in Rus).

Vasil'ev 2001 - Vasil'ev, VN 2001, K khronologii ranneprokhorovskogo klinkovogo oruzhiya i probleme III v. do n.eh., Materialy po arkheologii Volgo-Donskikh stepey, Volgograd, P.169-179. (Vasil'ev, VN 2001, To the chronology of the early Prokhorov blade weapon and the problem of the III century BC, Materials on archeology of Volga-Don steppes, Volgograd, P.169-179). (in Rus). 